\title{
Segurança dos alimentos: contaminação por Salmonella sp. no abate de suínos
} Food safety: Salmonella sp. contamination in swine slaughter

\author{
Deisi Carine Neitzke ${ }^{1 *}$, Cleber Rabelo da Roza ${ }^{2}$, Fernanda Hart Weber ${ }^{1}$ \\ ${ }^{1}$ Universidade Estadual do Rio Grande do Sul (UERGS), Três Passos/RS - Brasil \\ 2Universidade Estadual do Rio Grande do Sul (UERGS), Porto Alegre/RS - Brasil

\section{*Corresponding Author} \\ Deisi Carine Neitzke, Universidade Estadual do Rio Grande do Sul (UERGS), Rua Independência Esq. Castelo Branco, 1280, Érico Veríssimo, \\ CEP: 98600-000, Três Passos/RS - Brasil, e-mail: deisicn@gmail.com
}

Cite as: Food safety: Salmonella sp. contamination in swine slaughter. Braz. J. Food Technol., v. 20, e2015063, 2017.

Received: Aug. 20, 2015; Accepted: Mar. 06, 2017

\section{Resumo}

Este estudo teve o objetivo de avaliar a contaminação de carcaças suínas por Salmonella sp. em oito pontos específicos, no processo de abate de suínos, identificando a ocorrência e o motivo dessas contaminações. A pesquisa foi realizada em um frigorífico do Estado do Rio Grande do Sul, no período de abril a agosto de 2014. As amostras foram coletadas a partir de esfregaços, utilizando a técnica da esponja abrasiva em quatro regiões anatômicas na superfície da carcaça. A análise estatística foi realizada através do teste Qui-Quadrado. Trinta e três carcaças foram submetidas à coleta amostral, totalizando 258 amostras coletadas em todos os pontos. A partir da análise microbiológica, obteve-se uma frequência total de isolamento de Salmonella sp. igual a 7,75\% do total de amostras. De acordo com os resultados das análises estatísticas, não há diferença significativa entre os pontos amostrados, uma vez que as diferenças dos valores encontrados para o número de carcaças contaminadas por Salmonella sp. são baixas, mesmo comparando os pontos de maior contaminação com os de menor contaminação. O maior percentual de isolamento microbiano foi encontrado após a escaldagem e a depilação (ponto A), com $17,85 \%$. Os pontos B (após o toalete externo), C (seguido da abertura do abdômen) e E (imediatamente após a serragem das carcaças) apresentaram $10 \%$ de contaminantes cada. Os pontos $F$ (antes da lavagem final das carcaças) e H (após 24 horas de resfriamento) tiveram valores de 6,89\%, seguidos pelo ponto $\mathrm{G}$ (imediatamente após a lavagem final das carcaças, antes do resfriamento), com 3,33\%. O menor valor de contaminação foi encontrado no ponto $D$ (após a liberação do rabo), com 3,1\%. Assim, de acordo com os pontos amostrados, o frigorífico avaliado possui condições higienicossanitárias satisfatórias, de acordo com padrões estabelecidos internacionalmente e programas de controle, que favorecem as boas práticas de fabricação e avaliação dos pontos críticos de controle.

Palavras-chave: Segurança alimentar; Contaminação; Salmonella; Suínos.

\section{Summary}

This study aimed to evaluate the contamination of swine carcasses by Salmonella sp. at eight specific points in the swine slaughtering process, identifying the occurrence and the reasons for these contaminations. The survey was carried out in a swine processing plant in the state of Rio Grande do Sul, Brazil, in the period from April to August 2014. Samples were collected with swabs using the abrasive pad technique from four anatomical regions of the carcass surface. The statistical analysis was carried out using the chi-square test. Thirty-three carcasses were selected and subjected to sampling, giving a total of 258 samples collected at all points. The microbiological analyses showed a total frequency of Salmonella sp isolation equal to $7.75 \%$ of the total number of samples. According to the results of the statistical analyses, there were no significant differences between the points sampled, since the values found for the number of carcasses contaminated with Salmonella $\mathrm{sp}$. were low, even when comparing the more contaminated points with the less contaminated points. The highest percentage of microbial isolation was found after scalding and hair removal (point A) with $17.85 \%$. Points B (after external washing), C (after opening of the abdomen) and $E$ (immediately after sawing the carcass) each showed $10 \%$ of contaminants. Points $F$ (before the final washing of the carcasses) and $\mathrm{H}$ (after 24 hours of cooling) showed values of $6.89 \%$, followed by point $\mathrm{G}$ (immediately after the final washing of the carcasses and before cooling) which showed $3.33 \%$. The lowest contamination 
was found at point D (after release of the tail) with 3.1\%. Thus, according to the points sampled, the slaughterhouse examined had satisfactory hygienic and sanitary conditions in accordance with internationally established standards and control programs that support good manufacturing practices and the evaluation of critical control points.

Keywords: Food safety; Contamination; Salmonella; Swine.

\section{Introdução}

O desenvolvimento populacional aumentou significativamente a demanda por alimentos e, consequentemente, acentuou-se a busca constante dos consumidores por padrões que atendam à segurança alimentar e nutricional. Para alcançar estes objetivos, diversas adequações nas indústrias alimentícias foram necessárias, considerando-se que os alimentos frequentemente envolvidos em surtos de Doenças Transmitidas por Alimentos (DTA) são os produtos de origem animal. Patógenos podem contaminar as carcaças durante o abate ou podem, ainda, ser transportados de um ambiente, equipamento ou manipulador contaminado para as carcaças (MATSUBARA, 2005).

A presença de Salmonella sp. em sistemas de produção de suínos tem sido uma preocupação mundial, tanto por razões relacionadas à saúde pública como por barreiras econômicas (MULLER et al., 2009). Casos de infecção por Salmonella sp. foram relatados em rebanhos e amostras coletadas em carcaças durante o processo de abate (BESSA et al., 2004; KICH et al., 2005). Conforme Funk et al. (2001 apud GAMARRA, 2007), a partir da crescente ênfase na segurança de produtos cárneos que chegam ao consumidor, tem-se estimulado a identificação de meios para reduzir ou eliminar as taxas de Salmonella $\mathrm{sp}$. antes do abate, aumentando a segurança dos produtos cárneos. A redução deste patógeno no pré-abate pode garantir a redução da contaminação durante o abate. Além do status sanitário das granjas, a ração, o transporte e a espera pré-abate têm sido apontados como pontos críticos de contaminação por Salmonella sp. (ROSTAGNO et al., 2003).

As salmonelas localizam-se primordialmente em alimentos com alto teor de umidade e alta porcentagem de proteína, podendo a sua presença, em produtos cárneos crus, ser o resultado de ampla contaminação cruzada nas plantas industriais. Em pesquisas realizadas em ovinos por Fernandes et al. (2012), a presença de Salmonella sp. nessas amostras assume um caráter especial, quando se atenta para o fato de que sua presença no alimento não é denunciada pelos parâmetros de cor, aparência e aroma, destacando-se como causadora de toxi-infecções alimentares e comprometendo os alimentos ingeridos pela população, aspecto este crucial para a Saúde Pública (BESSA et al., 2004). Estudos revelam que a salmonelose é uma das principais zoonoses em todo o mundo, destacando-se pelas suas características de endemicidade e alta mortalidade, e, sobretudo, pela dificuldade da adoção de medida no seu controle (SHINOHARA et al., 2008). Entre os sorovares de Salmonella sp. que apresentam um risco maior à saúde pública, destacam-se $S$. Typhy e S. Paratyphy, que desenvolvem quadros clínicos graves no homem, como a febre tifoide e paratifoide. Os demais sorovares podem apresentar uma sintomatologia mais leve, como febre, dores abdominais, náuseas e vômitos (BARROS et al., 2002).

Intoxicações alimentares causadas por Salmonella spp. ocorrem mesmo em países desenvolvidos. No Brasil, supõe-se que a ocorrência de salmonelas seja relevante devido às deficiências de saneamento básico e às más condições higienicossanitárias da maioria da população, aliadas ao precário controle de qualidade de algumas indústrias alimentícias e de pequenos abatedouros (FUZIHARA et al., 2000). Nas unidades de processamento de carne, a Salmonella sp. pode ser frequentemente identificada nas mãos de manipuladores, sobre superfícies de trabalho e nos equipamentos, demonstrando que a contaminação cruzada entre carcaças pode ocorrer (GAMARRA, 2007).

A contaminação por Salmonella sp. pode ser controlada através de programas de Boas Práticas de Fabricação (BPF), as quais podem diminuir significativamente o risco de contaminação durante o processo de abate. Sistemas de controle, como Análise de Perigos e Pontos Críticos (APPC) e BPF, mostram-se eficientes para a eliminação deste microrganismo patogênico na produção de alimentos, considerando-se que o abate de suínos é um processo que oferece várias oportunidades de contaminação das carcaças (MACKEY; ROBERTS, 1993; GILL, 1995 apud MATSUBARA, 2005).

O presente estudo teve como objetivo avaliar a contaminação de carcaças suínas por Salmonella sp. em oito pontos específicos no abate de suínos, identificando quais destes pontos apresentam maior ocorrência de contaminação durante o processo de abate e os motivos dessas contaminações.

\section{Material e métodos}

A pesquisa foi desenvolvida em um frigorífico do Estado do Rio Grande do Sul, no período de abril a agosto de 2014. Os pontos de amostragem foram determinados de acordo com Lima et al. (2004), a partir da observação visual das operações durante o abate. Trinta e três carcaças foram selecionadas aleatoriamente, durante 0 
período de desenvolvimento da pesquisa. As carcaças foram selecionadas, identificadas e submetidas à coleta amostral em oito pontos: após a escaldagem e a depilação (ponto A), após o toalete externo (ponto B), seguido da abertura do abdômen (ponto C), após a liberação do rabo (ponto D), imediatamente após a serragem das carcaças (ponto E), antes da lavagem final das carcaças (ponto F), imediatamente após a lavagem final das carcaças antes do resfriamento (ponto $\mathrm{G}$ ) e após 24 horas de resfriamento (ponto H) do abate de suínos.

A coleta das amostras foi realizada utilizando-se a técnica da esponja abrasiva, previamente esterilizada e umedecida em uma câmara de fluxo laminar com água peptonada tamponada a 1\% estéril. Os esfregaços foram aplicados em quatro regiões anatômicas: pernil, paleta, lombo e barriga, totalizando uma área amostral de aproximadamente $400 \mathrm{~cm}^{2}$ em cada carcaça. A área coletada foi delimitada com a utilização de um molde de aço inoxidável desinfetado com álcool $70^{\circ} \mathrm{GL}$, a cada ponto de coleta. Para realização dos esfregaços, foram seguidas as orientações de Brasil (2007) descritas na Circular n. ${ }^{\circ} 130$.

As amostras foram encaminhadas para análise no Laboratório de Microbiologia do Frigorífico, onde foram realizados os ensaios qualitativos de detecção de Salmonella sp., através do Método da AOAC n. ${ }^{0}$ 11/2013 (AOAC, 2013), Teste Vidas (SML), que corresponde a um teste automatizado para detecção de Salmonella sp. em produtos alimentares. Neste, utiliza-se a mistura de anticorpos de captura com grande especificidade, dirigidos contra antígenos $\mathrm{O}$ e H. A técnica de detecção de microrganismos através de anticorpos fluorescentes, de acordo com Jay (2005), tem sido amplamente utilizada para detectar a presença de Salmonella sp. em amostras de diferentes alimentos.

A análise estatística foi realizada através do teste Qui-Quadrado, para verificar se houve diferença significativa entre os pontos de amostragem da coleta.

\section{Resultados e discussão}

Das 258 amostras coletadas, durante o processo de abate, obteve-se uma frequência total de isolamento de Salmonella sp. igual a 7,75\%. De acordo com o resultado das análises estatísticas, não há diferença significativa entre os pontos amostrados, uma vez que os valores encontrados para o número de carcaças contaminadas por Salmonella sp. são baixos, mesmo comparando-se os pontos de maior contaminação com os de menor contaminação. A frequência encontrada neste trabalho foi considerada relativamente baixa, quando comparada com os resultados descritos na literatura. Bessa et al. (2004), encontraram a prevalência de Salmonella sp. em 55,66\% de suas amostras de animais, no momento do abate. Já Lima et al. (2004), Matsubara (2005) e Gamarra (2007) encontraram em seus estudos, respectivamente, 11,70\%, $5,4 \%$ e 9,37\% de prevalência de Salmonella sp.

Existe uma preocupação crescente da indústria produtora de carne suína com a contaminação por Salmonella sp., pois esta bactéria contamina a superfície de carcaças suínas e entra na planta, a partir dos animais vivos e dos operários. A contaminação pode ocorrer principalmente pelo contato digestório de suínos portadores de Salmonella sp., que eliminam a bactéria com as fezes, contaminando o ambiente de alojamento e, consequentemente, outros animais, comprometendo toda a cadeia produtiva. Animais portadores de Salmonella sp. que não apresentam manifestações clínicas pela bactéria são de grande relevância para a saúde pública, pois contaminam o lote, novos grupos de animais no local de espera no frigorífico e, quando submetidos a situações de estresse, excretam o patógeno de forma intermitente. A carne e seus produtos podem estar expostos a contaminações em todas as fases de seu processamento, desde a manipulação sem cuidados específicos, fator este que tem, frequentemente, implicado na transmissão de patógenos para seres humanos, podendo o homem apresentar-se como um portador assintomático da bactéria (REZENDE, 2009; SAIDE-ALBORNOZ et al., 1995; ROSTAGNO et al., 2003; SPOLAORE, 2007; DUCAS; SILVA, 2011; PARDI et al., 2001; CAMPOS, 2004).

Na Tabela 1, está apresentado o número de amostras coletadas em cada ponto e o número de isolados de Salmonella sp. É possível observar que o maior percentual de isolamento foi encontrado no ponto $A(17,85 \%)$, seguido do ponto $\mathrm{B}$, ponto $\mathrm{C}$ e ponto $\mathrm{E}(10 \%)$; ponto $\mathrm{F}$ e ponto $H(6,89 \%)$ e ponto $G(3,33 \%)$, sendo o menor valor encontrado no ponto D (3,1\%). Os pontos F, G e H apresentaram um total de 31amostras coletadas, pois duas carcaças foram desviadas pelo Serviço de Inspeção Federal, impossibilitando a coleta nestes pontos.

O ponto A apresentou o maior número de amostras positivas, correspondendo a 17,85\% do total de amostras coletadas. Rezende (2009) isolou, neste mesmo ponto, um valor maior, sendo que $24,44 \%$ das suas amostras apresentaram Salmonella sp., enquanto Machado et al. (2013) relataram oito (20\%) amostras contaminadas, provenientes da pele após a escaldagem e a depilação, por Salmonella sp., valores maiores do que os encontrados por Seixas et al. (2009), que isolaram apenas uma amostra, correspondente a 5,55\% do total de amostras analisadas. Borch et al. (1996) e Berends et al. (1997) observaram que as etapas de escaldagem, depilação e evisceração requerem maiores cuidados, a fim de evitar que ocorra contaminação bacteriana, o que condiz com os resultados obtidos nesse ponto, neste trabalho. Conforme Gil e Bryant (1993), os equipamentos de depilação podem ser contaminados por Salmonella sp. presente na pele de alguns animais e podem transferir a bactéria para outras 
Segurança dos alimentos: contaminação por Salmonella sp. no abate de suínos

Neitzke, D. C. et al.

Tabela 1. Frequência de Isolados de Salmonella sp. em diferentes pontos de amostragem no abate de suínos.

\begin{tabular}{cccc}
\hline Ponto de Coleta & Negativos & Positivos & Total \\
A & 28 & 5 & 33 \\
B & 30 & 3 & 33 \\
C & 30 & 3 & 33 \\
D & 32 & 1 & 33 \\
E & 30 & 3 & 33 \\
F & 29 & 2 & 31 \\
G & 30 & 1 & 31 \\
H & 29 & 2 & 31 \\
Total & 238 & 20 & 258 \\
\hline
\end{tabular}

carcaças durante o processo de remoção das cerdas, pois não há higienização do equipamento entre a passagem de cada carcaça, podendo haver contaminação dos braços de borracha da depiladeira. Um dos fatores que também pode interferir na contaminação neste ponto de coleta é a temperatura da água. De acordo com Hald et al. (1999), manter a temperatura dessa água de escalda superior a $60^{\circ} \mathrm{C}$ evita a contaminação bacteriana das carcaças; assim, consideram o tanque de escalda um ponto crítico de controle.

De acordo com Rezende (2009), a presença de Salmonella sp. pode ser atribuída mais ao processo de depilação do que ao de escaldagem, já que a depiladeira é um equipamento de difícil higienização e fica próxima do tanque de escaldagem, sendo banhada constantemente com a água de escalda, que só é trocada ao final do abate; dessa forma, durante o processo, é introduzida determinada quantidade de água, que pode interferir também na contaminação por Salmonella sp.

Os pontos B e C apresentaram 10\% de suas amostras contaminadas por Salmonella sp. A ocorrência do patógeno no ponto B pode estar relacionada ao número de operadores que manipulam a carcaça após a chamuscagem, pois, antes deste ponto, são introduzidas diversas toaletes externas, aumentando a possibilidade de ocorrer contaminação cruzada. Já no ponto C, que corresponde ao local em que ocorre a abertura do abdômen, qualquer manipulação incorreta do operador pode ocasionar o rompimento das vísceras, podendo resultar em uma contaminação.

O ponto D apresentou uma das menores frequências de isolamento da bactéria - 3,1\% do total de amostras coletadas. Este valor relativamente baixo pode estar associado à prática adotada de oclusão do reto com saco plástico. De acordo com Borch et al. (1996), esse procedimento reduz expressivamente a contaminação microbiana de carcaças. Berends et al. (1997) também afirmam que a oclusão do reto evita $75 \%$ das contaminações de carcaças com Salmonella sp.

No ponto $E$, procede-se à remoção das vísceras brancas e, em sequência, a carcaça é dividida ao meio.
Este ponto apresentou 10\% de amostras positivas. Segundo Seixas et al. (2009), o isolamento do patógeno após a evisceração indica que pode ter ocorrido contaminação da carcaça no momento deste procedimento, com conteúdo fecal do próprio animal ou por contaminação cruzada, através de facas e/ou mãos do funcionário responsável pela evisceração. Os referidos autores sugerem, então, que se faça essa avaliação em trabalhos posteriores, no frigorífico estudado.

Durante a evisceração, pode ocorrer a ruptura das vísceras e, consequentemente, o extravasamento do conteúdo intestinal sobre as carcaças, podendo levar a uma subsequente contaminação cruzada (ZARDEH, 2001 apud DUCAS; SILVA, 2011). Lima et al. (2004) encontraram uma frequência de $16,70 \%$ de Salmonella sp. na mesma etapa do abate, justificando que o processo de evisceração é um dos principais fatores de contaminação de carcaças, nesta fase.

A carcaça de um suíno portador de Salmonella sp. nem sempre estará contaminada por este patógeno, caso a evisceração seja cuidadosamente conduzida. Por outro lado, carcaças de suíno livres de Salmonella sp. podem tornar-se positivas devido à contaminação cruzada por bactérias presentes em outras carcaças ou equipamentos (VAN DER GAAG et al., 2003 apud DUCAS; SILVA, 2011).

$O$ ponto $\mathrm{F}$ é aquele em que ocorre o monitoramento do operador, para identificar visualmente algum ponto de contaminação que pode comprometer a carcaça. Este ponto apresentou 6,89\% de suas amostras contaminadas. Nos pontos E e F, a carcaça é manipulada por diversos operadores, o que pode ter causado contaminação dessas carcaças.

O ponto amostral $\mathrm{G}$ foi coletado antes do resfriamento da carcaça, apresentando 3,33\% das amostras positivas para Salmonella sp., um valor superior ao encontrado por Machado et al. (2013), que isolaram a bactéria da pele de suínos após o chuveiro final do abate em 2,5\% das amostras coletadas.

Um valor maior foi relatado por Gamarra (2007), que obteve um total de $18,75 \%$ de amostras positivas após a lavagem final das carcaças. A ocorrência de 
amostras positivas no ponto $\mathrm{G}$ deste estudo corresponde ao que prevê o Ministério da Agricultura, Pecuária e Abastecimento, por meio de ofício circular interno, que normatiza critérios microbiológicos, para carcaças suínas, de controle de Salmonella sp., enterobactérias e microrganismos aeróbios mesófilos, destinadas a indústrias que exportam carne suína para os estados membros da União Europeia. Nestes estabelecimentos de abate de suínos, existe um plano de amostragem anual, pelo qual são realizadas, em dois ciclos, pesquisas de Salmonella sp. na superfície das carcaças. Em cada ciclo, composto de 50 carcaças, toleram-se cinco amostras positivas do mesmo lote para a bactéria (BRASIL, 2007). Note-se que o ponto $\mathrm{G}$ apresentou 3,33\% de amostras positivas para a bactéria, evidenciando resultados toleráveis para um ciclo amostral.

O ponto H demonstrou uma prevalência de 6,89\% de Salmonella sp., ocorrência que, segundo Ducas e Silva (2011), pode estar associada à manipulação das carcaças pelos operadores, pois os trilhos em questão são manuais e, para a carcaça ser estocada na câmara de resfriamento, é necessário o operário empurrá-la.

A Resolução RDC n. ${ }^{\circ} 12$ (BRASIL, 2001) estabelece padrões microbiológicos para produtos in natura e determina ausência de Salmonella sp. em cinco amostras analisadas aleatoriamente do mesmo lote, para o produto em distribuição no mercado interno. O perfil microbiológico da superfície das carcaças está diretamente relacionado a: i) carga e qualidade da microbiota contaminante inicial, em termos de gêneros e espécies; ii) dinâmica de redução de temperatura das carcaças, e iii) umidade relativa do ar dentro da câmara. Nottingham (1982) relata que, do ponto de vista de contenção da multiplicação microbiana, é desejável que, nas primeiras horas do resfriamento, atinjam-se rapidamente baixas temperaturas, entre $4^{\circ} \mathrm{C}$ e $7^{\circ} \mathrm{C}$, pois, desta forma, não haverá tempo de adaptação das bactérias e sua consequente multiplicação sobre a superfície da carcaça. Alterando-se temperatura, umidade relativa e velocidade do fluxo de ar na exposição das carcaças sob resfriamento, pode-se reduzir ou aumentar a concentração de microrganismos aeróbios superficiais. O resfriamento rápido e as baixas temperaturas com alta velocidade do ar circulante na câmara ocasionarão a desidratação superficial do produto e retardarão consideravelmente a multiplicação de bactérias gram-negativas.

A sobrevivência de Salmonella sp. ao processo de resfriamento constitui um problema importante para a saúde pública, haja vista que o tratamento das infecções causadas por cepas resistentes pode ser dificultado pela restrição de utilização de antibióticos (TAUXE, 1991). O isolamento de Salmonella sp. durante o processo de abate pode ser um indicativo de que a bactéria pode vir a contaminar o produto final, mesmo que os resultados apresentados neste trabalho atendam a legislações existentes. A ocorrência de Salmonella sp. na linha de abate sempre representa um risco para a saúde pública, tendo em vista a segurança alimentar dos consumidores. Dependendo da forma como forem conduzidas, as operações no processo de abate podem reduzir, mas não são capazes de eliminar totalmente, bactérias patogênicas e/ou deterioradoras de alimentos, que podem estar disseminadas nas etapas do abate (RIVAS et al., 2000 apud REZENDE, 2009).

Os resultados aqui apresentados confirmam certa variação, quando comparados aos relatados na literatura em relação à prevalência desta bactéria patogênica. Bessa et al. (2004) indicam que este fator pode estar relacionado não só a possíveis diferenças nos índices de portadores, devido ao tipo de exploração e fatores regionais, como também pela influência do método de amostragem realizado nos referidos estudos.

A presença de Salmonella sp. em animais que chegam ao frigorífico representa um fator de risco, mas não pode ser interpretada como um índice de contaminação do produto final. Quanto maior o número de animais que chegam portadores/excretores de Salmonella sp. no momento do abate, maior será a dificuldade de controlar os pontos críticos na indústria. Por esta razão, o número de animais portadores que chega ao abate tem sido apontado como primeiro ponto crítico de processamento, em relação a Salmonella sp. (BESSA et al., 2004).

\section{Considerações finais}

O índice de contaminação encontrado durante o processo de abate de suínos atende aos padrões legais vigentes no momento. Vale ressaltar que não existe uma relação de contaminação entre os pontos avaliados e as variações encontradas nos pontos amostrais, que podem estar relacionadas aos processos operacionais de higienização, com desvios pontuais durante o processo de abate, pela manipulação indevida de operadores ou inconformidades durante o processo de higienização em equipamentos e instalações do frigorífico em questão. É evidente que há uma série de fatores a ser considerados, o que demonstra a complexidade do abate de suínos.

Os Pontos Críticos de Controle são importantes para avaliação da contaminação por Salmonella sp. e programas que reforcem a importância das Boas Práticas de Fabricação, especialmente dos cuidados higiênicos em todas as etapas, são fundamentais, pois intensificam as medidas de higiene, evitam a contaminação cruzada e garantem a qualidade microbiológica do produto final, contribuindo para a fabricação de alimentos seguros.

\section{Referências}

ASSOCIATION OF OFFICIAL ANALYTICAL CHEMISTS - AOAC. Official Methods 2013.01: salmonella in a variety of foods VIDAS ${ }^{\circledR}$ UP Salmonella (SPT) method first action. Washington, 2013. 
Segurança dos alimentos: contaminação por Salmonella sp. no abate de suínos

Neitzke, D. C. et al.

BARROS, V. R. M.; PAIVA, P. C.; PENETTA, J. C. Salmonella spp: sua transmissão através dos alimentos. Higiene Alimentar, São Paulo, v. 16, n. 94, p. 15-19, 2002.

BERENDS, B. R.; VAN KNAPEN, F.; SNIJDERS, J. M. A.; MOSSEL, D. A. A. Identification and quantification of risk factors regarding Salmonella spp. on pork carcasses. International Journal of Food Microbiology, Amsterdam, v. 16, n. 2/3, p. 199-206, 1997. PMid:9217109. http://dx.doi.org/10.1016/S0168-1605(97)01267-1.

BESSA, M. C.; COSTA, M.; CARDOSO, M. Prevalência de Salmonella sp. em suínos abatidos em frigoríficos do Rio Grande do Sul (versão 2.0). Pesquisa Veterinária Brasileira, Rio de Janeiro, v. 2, n. 24, p. 80-84, 2004

BORCH, E.; NESBAKKEN, T.; CHRISTENSEN, H. Hazard identification in swine slaughter with respect to foodborne bacteria. International Journal of Food Microbiology, Amsterdam, v. 30, n. 1/2, p. 9-25, 1996. PMID: 8856371

BRASIL. Agência Nacional de Vigilância Sanitária. Resolução nº 12, de 02 de janeiro de 2001. Aprova e Regulamento Técnico sobre padrões microbiológicos para alimentos. Diário Oficial [da] República Federativa do Brasil, Brasília, DF, 10 jan. 2001.

BRASIL. Ministério da Agricultura, Pecuária e do Abastecimento. Institui a exportação de carne suínas para os estados-membros da União Europeia. Brasília: Ministério da Agricultura, Pecuária e do Abastecimento, 2007. Circular n 130/2007/CGPE/DIPOA.

CAMPOS, L. C. Salmonella. In: TRABULSI, L. R.; ALTERTHUM, F. Microbiologia. 4. ed. São Paulo: Atheneu, 2004. cap. 43, p. 319-328.

DUCAS, C. T. S.; SILVA, L. F. Pesquisa de Salmonella spp. e enumeração de coliformes totais e termotolerantes em carcaças de suínos abatidos em matadouro-frigorífico de Uberlândia, Minas Gerais (Versão 17). Veterinária Notícias, Uberlândia, v. 17, n. 1, p. 54-61, 2011.

FERNANDES, R. P. P.; FREIRE, M. T. A.; GUERRA, C. C.; CARRER, C. C.; BALIEIRO, J. C. C.; TRINDADE, M. A. Estabilidade físicoquímica, microbiológica e sensorial de carne ovina embalada a vácuo estocada sob refrigeração. Ciência Rural, Santa Maria, v. 42, n. 4, p. 724-729, 2012. http://dx.doi.org/10.1590/S010384782012000400025 .

FUZIHARA, T. O.; FERNANDES, S. A.; FRANCO, B. D. Prevalence and dissemination of Salmonella serotypes along the slaughtering process in Brazilian small poultry slaughterhouses. Journal of Food Protection, Des Moines, v. 63, n. 12, p. 1749-1753, 2000. PMid:11131902. http://dx.doi.org/10.4315/0362-028X-63.12.1749.

GAMARRA, R. M. Identificação de pontos críticos para Salmonella spp. no abate de suínos. 2007. 53 f. Dissertação (Mestrado Ciência e Tecnologia de Alimentos)-Universidade Federal de Santa Maria, Santa Maria, 2007

GILL, C. O.; BRYANT, J. The presence of Escherichia coli, Salmonella and Campylobacter in pig carcass dehairing equipments. Food Microbiology, Summit-Argo, v. 10, n. 4, p. 337-344, 1993. http:// dx.doi.org/10.1006/fmic.1993.1039.
HALD, T.; WINGSTRAND, A.; SWANENBURG, M.; ALTROCK, A. V.; LIMPITAKIS, N.; THORBERG, B-M. Harvest epidemiology of Salmonella contamination in EU pig slaughterhouses. In: INTERNATIONAL SYMPOSIUM ON THE EPIDEMIOLOGY AND CONTROL OF SALMONELLA IN PORK, 3., 1999, Washington. Proceedings... Ames: lowa State University, 1999. p. 273-276.

JAY, J. M. Microbiologia de alimentos. 6. ed. Porto Alegre: Artmed, 2005.

KICH, J. D.; MORES, N.; PIFFER, I. A.; COLDEBELLA, A.; AMARAL, A.; RAMMINGER, L.; CARDOSO, M. Fatores associados à soroprevalência de Salmonella em rebanhos comerciais de suínos (versão 35). Ciência Rural, Santa Maria, v. 35, n. 4, p. 337-344, 2005. http://dx.doi.org/10.1590/S0103-84782005000200024.

LIMA, E. S. C.; PINTO, P. S. A.; SANTOS, J. L.; VANETTI, M. C. D.; BEVILACQUA, P. D.; ALMEIDA, L. P.; PINTO, M. S.; DIAS, F. S. Isolamento de Salmonella sp e Staphylococcus aureus no processo do abate suíno como subsídio ao sistema de Análise de Perigos e Pontos Críticos de Controle - APPCC. Pesquisa Veterinária Brasileira, Rio de Janeiro, v. 24, n. 4, p. 185-190, 2004.

MACHADO, A. R.; GOUVEIA, F. C.; PICININ, L. C. A.; KICH, J. D.; CARDOSO, M. R. I.; FERRAZ, S. M. Avaliação microbiológica e físico-química de pernis suínos tratados com ácidos orgânicos e/ ou vapor no controle da contaminação superficial por Salmonella Typhimurium. Ciência Animal Brasileira, Goiás, v. 14, n. 13, p. 185-190, 2013.

MACKEY, B. M.; ROBERTS, T. A. Improving slaughter hygiene using HACCP and monitoring. Fleischwirtschaft International, v. 2, p. 40-45, 1993.

MATSUBARA, E. N. Condições higiênico-sanitárias de meiascarcaças de suínos após o abate e depois de resfriamento e análise da utilização de Lista de Verificação para avaliar boas práticas no abate de suínos. 2005. 154 f. Dissertação (Mestrado em Medicina Veterinária Preventiva e Saúde Animal)Faculdade de Medicina Veterinária, Universidade de São Paulo, São Paulo, 2005.

MÜLLER, M.; SCHWARZ, P.; KICH, J. D.; CARDOSO, M. Perfil sorológico e de isolamento de Salmonella sp. em suínos no início da terminação e ao abate. Ciência Animal Brasileira, Goiás, v. 10, n. 3, p. 931-937, 2009.

NOTTINGHAM, P. M. Microbiology of carcass meat. In: BROWN, M. H. Meat microbiology. London: Applied Science Publishers, 1982. p. 13-65.

PARDI, M. C.; SANTOS, I. F.; SOUZA, E. R.; PARDI, H. S. Ciência, higiene e tecnologia da carne: tecnologia da sua obtenção e transformação. 2. ed. Goiânia: Editora UFG, 2001. v. 1.

REZENDE, M. T. N. P. Salmonella sp. em rebanho comercial de suínos e suas carcaças processadas no frigorífico. 2009. 92 f. Dissertação (Mestrado em Ciências Veterinárias)-Faculdade de Medicina Veterinária, Universidade Federal de Uberlândia, Uberlândia, 2009 . 
Segurança dos alimentos: contaminação por Salmonella sp. no abate de suínos

Neitzke, D. C. et al.

ROSTAGNO, M. H.; HURD, H. S.; MCKEAN, J. D.; ZIEMER, C. J.; GAILEY, J. K.; LEITE, R. C. Preslaughter holding environment in pork plants is highly contaminated with Salmonella enterica. Applied and Environmental Microbiology, Washington, v. 69, n. 8, p. 4489-4494, 2003. PMid:12902233. http://dx.doi.org/10.1128/ AEM.69.8.4489-4494.2003.

SAIDE-ALBORNOZ, J. J.; KNIPE, C. L.; MURANO, E. A.; BERAN, G. W. Contamination of pork carcasses during slaughter, fabrication, and chilled storage (version 58). Journal of Food Protection, Des Moines, v. 58, n. 9, p. 993-997, 1995. http:// dx.doi.org/10.4315/0362-028X-58.9.993.

SEIXAS, F. N.; TOCHETTO, R.; FERRAZ, S. M. Presença de Salmonella em Carcaças Suínas amostradas em diferentes pontos da linha de processamento (versão 10). Ciência Animal Brasileira, Goiás, v. 10, n. 2, p. 634-640, 2009.
SHINOHARA, N. K. S.; BARROS, V. B.; JIMENEZ, S. M. C.; MACHADO, E. C. L.; DUTRA, R. A. F.; LIMA FILHO, J. L. Salmonella spp., importante agente patogênico veiculado em alimentos. Ciência e Saúde Coletiva, Rio de Janeiro, v. 5, n. 13, p. 16751683, 2008. http://dx. doi.org/10.1590/S1413-81232008000500031.

SPOLAORE, A. J. G. Prevalência de Salmonella sp. em linfonodos mesentéricos de suínos abatidos na região oeste do Paraná e potencial de disseminação em bandejas, facas, e luvas de manipuladores durante a inspeção post-mortem. 2007. 61 f. Dissertação (Mestrado Ciências Veterinárias do Setor de Ciências Agrárias)-Universidade Federal do Paraná, Curitiba, 2007.

TAUXE, R. V. Salmonella: a postmodern pathogen. Journal of Food Protection, Des Moines, v. 54, n. 7, p. 563-568, 1991. http://dx.doi.org/10.4315/0362-028X-54.7.563. 